\title{
Faktor Yang Mempengaruhi Continuance Intention GO-PAY Di Jakarta
}

\author{
Geraldi Tekaqnetha dan Rodhiah \\ Program Studi Manajemen Fakultas Ekonomi Universitas Tarumanagara Jakarta \\ Email: geraldi.115150364@stu.untar.ac.id
}

\begin{abstract}
The purpose of this research is to determine whether habit, perceived usefulness, perceived enjoyment, and perceived ease of use can affect the continuance intention of Gopay in West Jakarta. The population of this research is people who have or have obtained service from Go-pay. In this reasearch using sample with purposive sampling techniques distributed to 100 respondents. The data analysis technique used is multiple regression analysis in the SPSS 25 program. The results of this research are habit, perceived usefulness, and perceived enjoyment that have a significant influence of continuance intention, while perceived ease of use has a non-significant influence of continuance intention.
\end{abstract}

Keywords: Habit (H), Perceived Usedulness (PU), Perceived Enjoyment (PE), Perceived Ease Of Use (PEOU) dan Continuance Intention (CI).

Abstrak: Tujuan dari penelitian ini untuk mengetahui apakah habit, perceived usefulness, perceived enjoyment, dan perceived ease of use dapat mempengaruhi continuance intention Go-pay di Jakarta Barat. Populasi penelitian ini adalah orang yang pernah atau sudah menggunakan layanan dari Go-pay. Penelitian ini menggunakan sampel dengan teknik purposive sampling yang dibagikan kepada 100 orang responden. Teknik analisis data yang digunakan adalah analisis regresi ganda dalam program SPSS 25. Hasil dari penelitian ini adalah habit, perceived usefulness, dan perceived enjoyment memiliki pengaruh yang signifikan terhadap continuance intention, sedangkan perceived ease of use memiliki pengaruh yang tidak signifikan terhadap continuance intention.

Kata Kunci: Habit (H), Perceived Usedulness (PU), Perceived Enjoyment (PE), Perceived Ease Of Use (PEOU) dan Continuance Intention (CI).

\section{LATAR BELAKANG}

Saat ini mobile payment sedang populer digunakan oleh masyarakat, mobile payment sendiri bearti pengguna mengadopsi terminal seluler seperti ponsel untuk melakukan pembayaran tagihan, barang, dan layanan Zhou, T, (2013). Di Indonesia sendiri banyak perusahaan yang memberikan layanan mobile payment, menurut data dari dailysocial layanan ini sudah ada di Indonesia sejak tahun 2007 saat itu adalah T-cash. Walaupun Tcash merupakan layanan mobile payment yang pertama di Indonesia, tetapi saat ini T-cash bukanlah penguasa dalam layanan mobile payment di Indonesia, karena dapat disaingi oleh Go-pay.

Go-pay merupakan aplikasi yang baru dalam layanan mobile payment di Indonesia, dari data dailysocial Go-pay muncul pada tahun 2016. Walaupun masih baru dalam masyarakat, saat ini aplikasi ini menjadi yang cukup sering digunakan. Oleh karena itu hal ini menjadi menarik untuk di teliti, bagaimana Go-pay dapat membuat pelanggannya untuk terus mempertahankan continuance intention terhadap Go-pay. 
Dari data diatas maka, akan dilakukan analisis beberapa faktor yang mempengaruhi continuance intention pada pelanggan Go-pay di Jakarta yaitu, habit, perceived usefulness, perceived enjoyment, dan perceived ease of use.

\section{KAJIAN TEORI}

\section{Habit dan Continuance Intention}

Menurut Gan, Chunmei; Liang, Xubin; and Yu, Xinyan (2017) habit adalah urutan tindakan yang dipelajari yang telah menjadi respons otomatis terhadap situasi tertentu, yang mungkin fungsional dalam mencapai tujuan atau keadaan akhir tertentu. Menurut Gardner, B. (2015) habit sebagai suatu proses di mana suatu stimulus menghasilkan suatu dorongan untuk bertindak sebagai hasil dari asosiasi stimulus-respons yang dipelajari. Dalam penelitian Amoroso, D., \& Lim, R. (2017) ketika seseorang menjadi lebih puas, ia akan merasakan habit, tetapi sebaliknya jika orang tersebut merasakan kepuasan yang rendah, maka akan semakin rendah juga habit.

\section{Perceived Usefulness dan Continuance Intention}

Kim, B. (2011) mendefinisikan perceived usefulness dapat diartikan sejauh mana pengguna percaya bahwa menggunakan sistem informasi akan meningkatkan kinerja mereka dalam mencapai tujuan mereka Kemudian menurut Chang, (2008) perceived usefulness merupakan sejauh mana pengguna secara subjektif percaya situs web agen dapat membantu pengguna dalam merealisasikan targetnya. Dalam penelitian Ali, V., Merrill, W. (2016) perceived usefulness penting bagi continuance intention, tetapi efeknya tidak tergantung pada kepuasan, karena kepuasan hanya menangkap pengalaman pengguna masa lalu, sedangkan perceived usefulness mewakili manfaat yang diharapkan dari penggunaan masa mendatang.

\section{Perceived Enjoyment dan Continuance Intention}

Hsiao, K-L. (2017) perceived enjoyment bisa diartikan sebagai kesenangan subjektif yang dirasakan individu ketika terlibat dalam perilaku atau aktivitas tertentu. Kemudian Lin, X., Featherman, M., \& Sarker, S. (2017) juga mengartikan perceived enjoyment merupakan sejauh mana aktivitas menggunakan komputer dianggap menyenangkan dalam dirinya sendiri, terlepas dari konsekuensi yang dapat diantisipasi. Menurut penelitian Gan, C., \& Li, H. (2018) yang meneliti tentang we chat menjelaskan bahwa penggunaan aplikasi tersebut dapat membantu para pengguna untuk menghabiskan waktu senggang mereka, jika we chat dapat membantu mereka menghabiskan waktu senggang mereka maka continuance intention dapat muncul.

\section{Perceived Ease of Use dan Continuance Intention}

Hamid, A. A., Razak, F. Z. A., Bakar, A. A., \& Abdullah, W. S. W. (2016) menjelaskan perceived ease of use adalah sejauh mana seseorang percaya bahwa menggunakan suatu sistem tertentu akan bebas dari usaha Kemudian Rouibah, K., Abbas, H., \& Rouibah, S. (2011) mengatakan perceived ease of use merupakan sejauh mana seseorang percaya bahwa dengan menggunakan teknologi mereka akan bebas dari segala upaya mental. Menurut Chong, A. Y.-L. (2013) menjelaskan bahwa perceived ease of use dapat memiliki pengaruh yang baik, karena semakin maju teknologi maka akan muncul teknologi yang baru sehingga akan membuat pengguna sedikit kesusahan dalam menggunakannya. Oleh karena itu jika 
pengguna sudah terbiasa dengan suatu teknologi yang gampang maka pengguna akan menggunakannya secara berlanjut.

\section{Continuance Intention}

Menurut Amoroso, D., \& Lim, R. (2017) continuance intention merupakan tingkat kekuatan niat individu untuk melakukan pembelian berulang kali melalui aplikasi seluler finansial. Sementara itu (Bhattacherjee 2001) menjelaskan continuance intention adalah penggunaan berkelanjutan sistem informasi oleh pengadopsi, di mana keputusan kelanjutan mengikuti keputusan penerimaan awal.

Berdasarkan dari penjelasan setiap variabel di atas, habit, perceived usefulness, perceived enjoyment, dan perceived ease of use memiliki pengaruh terhadap continuance intention.

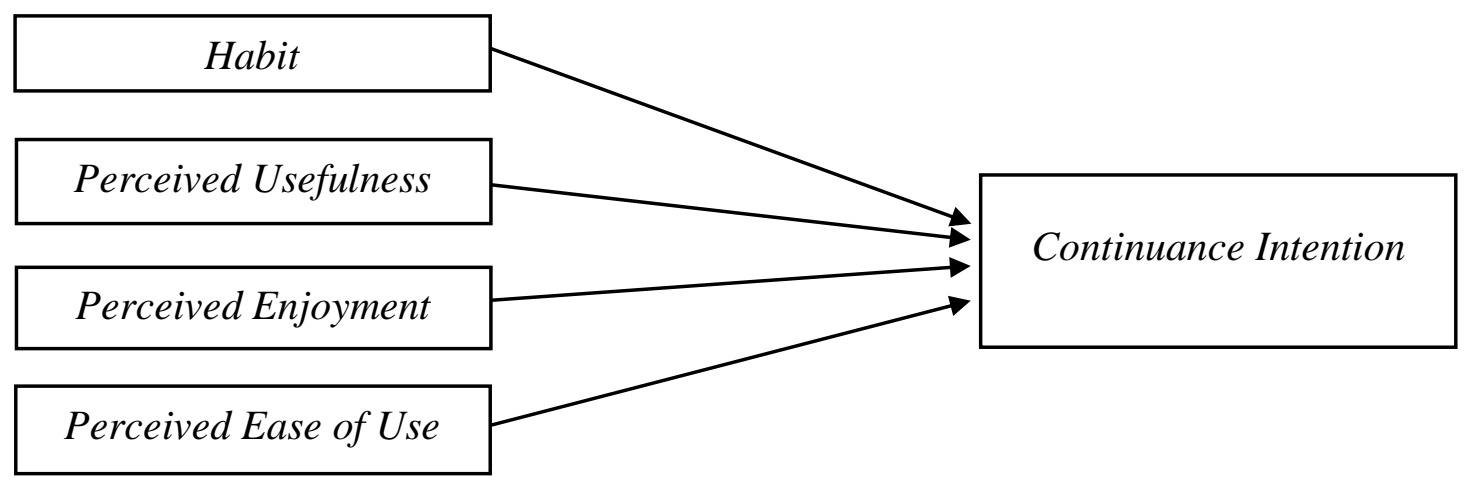

Gambar 1. Model Penelitian

Hipotesis dari model yang dibangun di atas adalah sebagai berikut :

H1 : Habit dapat digunakan untuk mempengaruhi continuance intention pengguna Go-Pay

$\mathrm{H} 2$ : Perceived usefulness dapat digunakan untuk mempengaruhi continuance intention pengguna Go-Pay

H3 : Perceived enjoyment dapat digunakan untuk mempengaruhi continuance intention pengguna Go-Pay

$\mathrm{H} 4$ : Perceived ease of use dapat digunakan untuk mepengaruhi continuance intention pengguna Go-Pay

\section{METODOLOGI}

Pengambilan sampel penelitian ini menggunakan purposive sampling yang disebarkan dengan menggunakan google form dimana responden diminta untuk memberi tanggapan terhadap pernyataan-pernyataan yang terdapat pada kuesioner yang diukur dengan skala Likert. Sampel yang digunakan sebanyak 100 responden yang merupakan pelanggan Gopay yang berada di Jakarta Barat. Analisa data pada penelitian ini menggunakan metode SPSS dengan menggunakan software SPSS versi 25. 


\section{Hasil Analisa Data}

Subjek penelitian terdiri dari 55 pria dan 45 wanita, dengan mayoritas responden berpendidikan terakhir SMA sebesar 59\%. Responden mayoritas berusia 17-22 tahun. Mayoritas pekerjaan responden adalah sebagai pelajar / mahasiswa yaitu sebesar 55\%. Alasan mereka menggunakan Go-pay mayoritas menjawab karena mudah, yaitu sebanyak 55 responden. Pengeluaran per bulan responden mayoritas menjawab Rp.800.000,00 Rp.2.000.000,00 sebanyak 53 responden. Mayoritas responden menggunakan Go-pay sebanyak 4-6 kali dan 1-3 kali dalam seminggu yaitu sebanyak masing-masing 33 responden. Responden menggunakan Go-pay mayoritas menjawab untuk membayar layanan Go-jek dan untuk membayar barang belanjaan yaitu sebanyak 53 responden. Dan responden mayoritas berdomisili di Grogol Petamburan yaitu sebanyak 37 responden. Analisa data menggunakan SPSS, yakni Uji validitas dan reliabilitas, uji asumsi analisis data, uji regresi ganda, uji T, uji F, dan koefisien determinasi:

\section{Hasil Uji Validitas dan Reliabilitas}

Menurut Ghozali (2016), Uji validitas digunakan untuk mengukur sah atau valid tidaknya suatu kuesioner. Sedangkan uji reliabilitas sebenarnya adalah alat untuk mengukur suatu kuesioner yang merupakan indikator dari variabel atau konstruk Ghozali (2016).

Tabel 1. Hasil uji Validitas

\begin{tabular}{|c|c|c|}
\hline Pernyataan & Nilai Validitas & Keterangan \\
\hline $\mathrm{H} 1$ & 0.756 & Valid \\
\hline $\mathrm{H} 2$ & 0.725 & Valid \\
\hline $\mathrm{H} 3$ & 0.828 & Valid \\
\hline $\mathrm{H} 4$ & 0.728 & Valid \\
\hline H5 & 0.624 & Valid \\
\hline PU1 & 0.656 & Valid \\
\hline PU2 & 0.630 & Valid \\
\hline PU3 & 0.568 & Valid \\
\hline PU4 & 0.565 & Valid \\
\hline PU5 & 0.408 & Valid \\
\hline PU6 & 0.621 & Valid \\
\hline PE1 & 0.653 & Valid \\
\hline PE2 & 0.643 & Valid \\
\hline PE3 & 0.639 & Valid \\
\hline PE4 & 0.773 & Valid \\
\hline PEOU1 & 0.593 & Valid \\
\hline PEOU2 & 0.658 & Valid \\
\hline PEOU3 & 0.734 & Valid \\
\hline PEOU4 & 0.650 & Valid \\
\hline CI1 & 0.656 & Valid \\
\hline $\mathrm{CI} 2$ & 0.707 & Valid \\
\hline $\mathrm{CI} 3$ & 0.737 & Valid \\
\hline CI4 & 0.642 & Valid \\
\hline CI5 & 0.512 & Valid \\
\hline
\end{tabular}


Dari data yang telah disajikan di atas seluruh variabel lolos dari uji validitas dikarenakan nilai validitasnya diatas atau sama dengan 0,3 .

Tabel 2. Hasil uji validitas

\begin{tabular}{|l|l|l|}
\hline Variabel & Nilai Alpha Cronbach & Keterangan \\
\hline Habit & 0.887 & Reliabel \\
\hline Perceived Usefulness & 0.807 & Reliabel \\
\hline Perceived Enjoyment & 0.839 & Reliabel \\
\hline Perceived Ease of Use & 0.830 & Reliabel \\
\hline Continuance Intention & 0.835 & Reliabel \\
\hline
\end{tabular}

Dari data yang telah dipaparkan diatas, seluruh variabel mulai dari variabel habit, perceived usefulness, perceived enjoyment, perceived ease of use, dan continuance intention lolos dari uji reliabilitas, karena nilai dari alpha cronbach nya diatas 0.6.

Tabel 3. Hasil Uji Multikolinearitas

\begin{tabular}{|l|l|l|l|}
\hline Variabel & $\begin{array}{l}\text { Collinearity } \\
\text { Tolerance }\end{array}$ & VIF & Keterangan \\
\hline Habit & 0.501 & 1.997 & $\begin{array}{l}\text { Tidak terdapat } \\
\text { multikolinearitas }\end{array}$ \\
\hline $\begin{array}{l}\text { Perceived terdapat } \\
\text { Usefulness }\end{array}$ & 0.451 & 2.218 & $\begin{array}{l}\text { Tidak terdapat } \\
\text { multikolinearitas }\end{array}$ \\
\hline $\begin{array}{l}\text { Perceived } \\
\text { Enjoyment }\end{array}$ & 0.430 & 2.325 & $\begin{array}{l}\text { Tidak } \\
\text { multikolinearitas }\end{array}$ \\
\hline $\begin{array}{l}\text { Perceived Ease of } \\
\text { Use }\end{array}$ & 0.446 & 2.242 & $\begin{array}{l}\text { Tidak terdapat } \\
\text { multikolinearitas }\end{array}$ \\
\hline
\end{tabular}

Berdasarkan data yang telah disajikan diatas seluruh variabel tidak terdapat multikolinearitas karena nilai VIF nya berada dibawah 10.

Gambar 2. Hasil Uji Heterokedastisitas

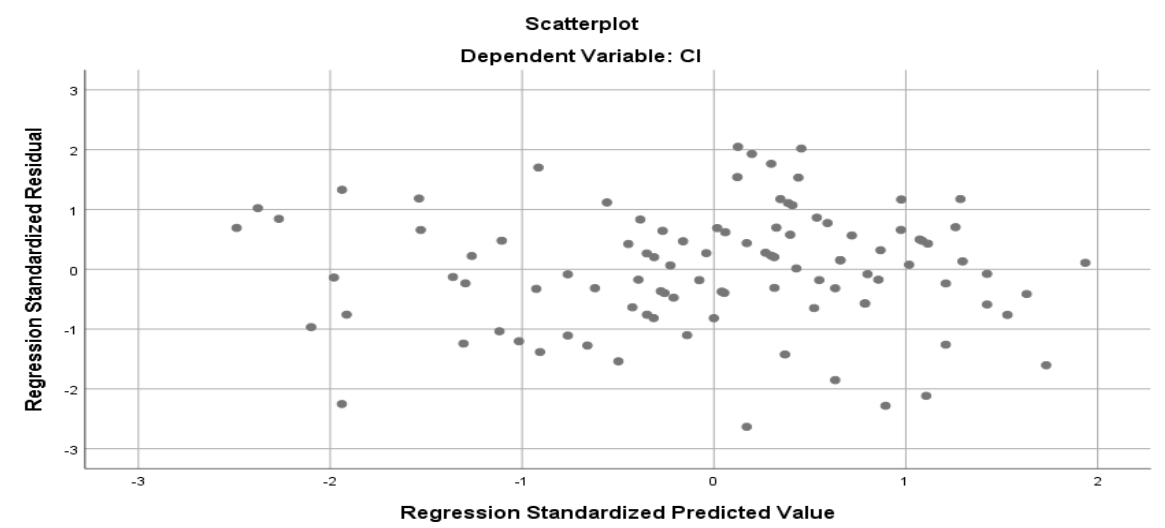


Berdasarkan gambar yang dipaparkan diatas, dapat disimpulkan bahwa data yang dihasilkan terdapat penyebaran atau tidak bertumpuk di satu posisi, sehingga peneliti dapat menyimpulkan bahwa penelitian ini lolos dari uji heterokedastisitas.

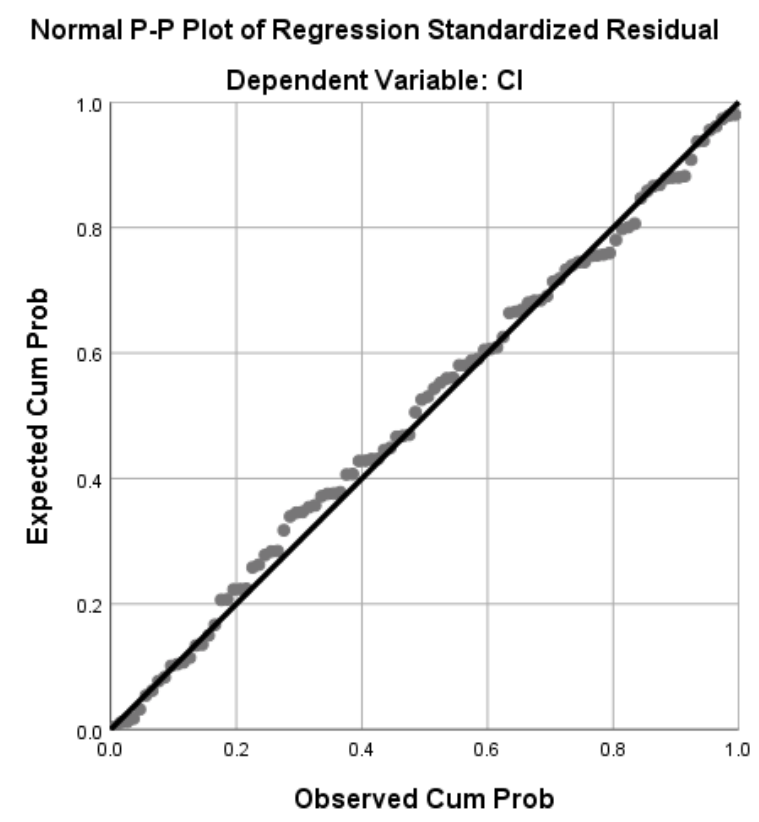

Gambar 3. Hasil Uji Normalitas

Berdasarkan dari gambar diatas, dapat disimpulkan bahwa data bersifat normal karena titik - titik yang direpresentasikan masih sekitar garis lurus sehingga seluruh data pengujian penelitian ini normal.

Tabel 4. Hasil Uji Analisis Regresi Ganda

\begin{tabular}{|c|c|}
\hline Variabel & Nilai Regresi \\
\hline Konstan & -0.317 \\
\hline Habit & 0.163 \\
\hline Perceived Usefulness & 0.244 \\
\hline Perceived Enjoyment & 0.572 \\
\hline Perceived Ease of Use & 0.076 \\
\hline
\end{tabular}

Dari data diatas rumus persamaan regresi pada penelitian ini adalah :

$\mathrm{Y}=\mathrm{a}+\mathrm{b} 1 \mathrm{X} 1+\mathrm{b} 2 \mathrm{X} 2+\mathrm{b} 3 \mathrm{X} 3+\mathrm{b} 4 \mathrm{X} 4$

Continuance Intention $=-0.317+0.163($ Habit $)+0.244($ Perceived Usefulness $)+$ 0.572 (Perceived Enjoyment $)+0.076$ (Perceived Ease of Use)

Tabel 5. Hasil Uji F

\begin{tabular}{|l|l|l|}
\hline & F & Sig \\
\hline Regresi & 66.215 & $0.000^{\mathrm{b}}$ \\
\hline Residual & & \\
\hline
\end{tabular}


Berdasarkan uji anova yang telah dipaparkan diatas, maka dapat disimpulkan bahwa uji anova lolos karena angka signifikan sebesar 0.000 dimana bila sig $<0.05$ maka dari itu minimal ada satu variabel independen (habit, perceived usefulness, perceived enjoyment, dan perceived ease of use) dapat mempengaruhi variabel dependen (continuance intention).

Tabel 6. Hasil Uji T

\begin{tabular}{|c|c|}
\hline Variabel & p-value \\
\hline Habit & 0.013 \\
\hline Perceived Usefulness & 0.036 \\
\hline Perceived Enjoyment & 0.000 \\
\hline Perceived Ease of Use & 0.423 \\
\hline
\end{tabular}

Berdasarkan data yang telah dipaparkan diatas, variabel diatas akan lolos uji T jika pvalue berada di atas 0.05. Variabel habit perceived usefulness, dan perceived enjoyment memiliki pengaruh yang positif terhadap continuance intention, karena p-value nya berada dibawah 0.05 . sedangkan perceived ease of use memiliki pengaruh yang negatif terhadap continuance intention, karena p-value berada di atas 0.05 .

Tabel 7. Hasil Uji Koefisien Determinasi

\begin{tabular}{|c|c|c|}
\hline Model & R Square & Adjusted R Square \\
\hline 1 & 0.736 & 0.725 \\
\hline
\end{tabular}

Pada tabel diatas, menunjukan bahwa variabel independent (habit, perceived usefulness, perceived enjoyment, dan perceived ease of use) menunjukan adjusted R square sebesar 0.725 yang bearti continuance intention Go-pay di Jakarta dapat dijelaskan oleh variabel independent sebesar $72,5 \%$ dan $27,5 \%$ dijelaskan oleh variabel lainnya.

\section{DISKUSI}

Berdasarkan hasil dari pengujian ini, peneliti dapat menyimpulkan bahwa habit, perceived usefulness, dan perceived enjoyment memiliki pengaruh yang signifikan terhadap continuance intention Go-pay. Karena seluruh P-value nya berada diatas 0.05. Kemudian perceived ease of use memiliki pengaruh yang tidak signifikan terhadap continuance intention Go-pay. karena P-value nya berada dibawah 0.05

\section{PENUTUP}

Dari hasil penelitian ini yang terdapat dalam Bab VI, maka dapat disimpulkan sebagai berikut :

1. Habit memiliki pengaruh yang signifikan terhadap continuance intention Go-pay di Jakarta. Pelanggan yang memiliki habit terhadap Go-pay akan dapat meningkatkan continuance intention.

2. Perceived usefulness memiliki pengaruh dan signifikan terhadap continuance intention Go-pay di Jakarta. Pelanggan yang merasa perceived usefulness dari Gopay akan dapat meningkatkan continuance intention. 
3. Perceived enjoyment memiliki pengaruh yang signifikan terhadap continuance intention Go-pay di Jakarta. Pelanggan yang merasa perceived enjoyment dari Gopay akan dapat meningkatkan continuance intention.

4. Perceived ease of use memiliki pengaruh yang tidak signifikan terhadap continuance intention Go-pay di Jakarta. Dengan adanya perceived ease of use bagi pelanggan Go-pay bukan bearti dapat meningkatkan continuance intention Go-pay.

Dalam hasil penelitian ini, maka peneliti akan memberikan beberapa saran yang kiranya akan bermanfaat, baik bagi perusahaan maupun bagi peneliti lain, yaitu sebagai berikut :

1. Dalam penelitian ini pelanggan yang memiliki habit terhadap panggunaan Gopay memang dapat mempengaruhi continunce intention, akan tetapi bagi pelanggan Go-pay, mereka merasa tidak sulit untuk menghentikan penggunaan Go-pay. karena itu penting bagi Go-pay untuk terus memelihara habit yang ada pada pelanggan mereka agar tercapai continuance intention penggunaan Go-pay.

2. Pelanggan Go-pay merasa, dalam menggunakan Go-pay mereka tidak merasakan aplikasi Go-pay membuat mereka melakukan transaksi lebih murah. Oleh karena itu, penting bagi Go-pay untuk membuat pelanggan mereka merasakan perceived usefulness yang lebih dari pengunaan aplikasi Go-pay, agar continuance intention tersebut tercapai.

3. Dalam menggunakan aplikasi Go-pay, perceived enjoyment merupakan hal penting bagi para pelanggan. Karena itu Go-pay perlu meningkatkan pelayanan mereka, agar pelanggan yang merasa nyaman dalam menggunakan Go-pay dapat berharap lebih terhadap Go-pay, sehingga continuance intention terhadap Go-pay akan tercapai.

\section{DAFTAR PUSTAKA}

Amoroso, D., \& Lim, R. (2017). The mediating effects of habit on continuance intention. International Journal of Information Management, 37(6), 693-702.

Bhattacherjee, A. (2001). An empirical analysis of the antecedents of electronic commerce service continuance. Decision Support Systems, 32(2), 201-214.

Chang, H. H. (2008). Intelligent agents technology characteristics applied to online auctions' task: A combined model of TTF and TAM. Technovation, 28(9), 564-577.

Chong, A. Y. (2013). Understanding Mobile Commerce Continuance Intentions: An Empirical Analysis of Chinese Consumers. Journal of Computer Information Systems, 53(4), 22-30. 
Eka, R. "Tren Perkembangan "Moile Payment" di Indonesia" 6 Maret (2018). https://dailysocial.id/post/perkembangan-mobile-payment-indonesia

Gan, C., \& Li, H. (2018). Understanding the effects of gratifications on the continuance intention to use WeChat in China: A perspective on uses and gratifications. Computers in Human Behavior, 78, 306-315.

Gan,C. Liang, X. Yu, X. (2017) Continuance Intention on Mobile Social Networking Service : Examine the Effects of Habit and Gratifications. WHICEB 2017 Proceedings. 44.

Gardener. B (2015). A review and Analysis of the use of 'habit' in understanding, prediciting and influencing health-related behaviour. Heatlh Psychology Review, Vol 9, No3, 277 295 ISSN : 1743-7199.

Ghozali, Imam. 2016. Aplikasi Analisis Multivariete Dengan Program IBM SPSS 23 (Edisi 8). Cetakan ke VIII. Semarang : Badan Penerbit Universitas Diponegoro

Hamid, A.A. Razak , F.Z. A. Bakar, A.A. Abdullah, W.S.W. (2016). The Effects of Perceived Usefulness and Perceived Ease Of Use On Continuance Intention To Use E - Government. Procedia Economic aand Finance. 35 (2016 644-649).

Hsiao, K. L. (2017). What drives continuance intention to share location-based information? International Journal of Mobile Communications, 15(2), 210.

Kim, B. (2011). Understanding Antecedents of Continuance Intention in Social-Networking Services. Cyberpsychology, Behavior, and Social Networking, 14(4), 199-205.

Lin, X., Featherman, M., \& Sarker, S. (2017). Understanding factors affecting users' social networking site continuance: A gender difference perspective. Information \& Management, 54(3), 383-395.

Rouibah, K., Abbas, H., \& Rouibah, S. (2011). Factors affecting camera mobile phone adoption before e-shopping in the Arab world. Technology in Society, 33(3-4), 271283.

Vedadi, A., \& Warkentin, M. (2016). Continuance Intention on Using Mobile Banking Applications: A Replication Study of Information Systems Continuance Model. AIS Transactions on Replication Research, 2, 1-11.

Zhou, T. (2013). An empirical examination of continuance intention of mobile payment services. Decision Support Systems, 54(2), 1085-1091. 